\title{
Developing And Delivering The Virtual MBA Course
}

Roy D. Johnson, (Email: roy@gsu.edu), Georgia State University Carl H. Stucke, (Email: cstucke@ cis.gsu.edu), Georgia State University

\begin{abstract}
The use of the Internet offers a unique opportunity to bring together individuals in an interactive setting for social and educational purposes. Colleges and universities have augmented their brick and mortar classes with virtual course offerings using the Internet for distance education. This paper will examine the origins of distance education and offer insights and recommendations for developing and delivering an on-line MBA course in Privacy and Information Security.
\end{abstract}

\section{INTRODUCTION}

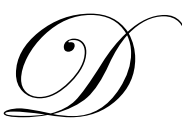

istance education originated during the industrial revolution based on the need for an educated work force and was codified in the 19th century with correspondence courses using printed materials and the postal system to connect students with instructors (Sumner, 2000). In 1840, Isaac Pitman offered the first correspondence course for shorthand in England (Verduin \& Clark, 1991). By the end of the century American, Canadian and European universities offered distance education courses (Sumner, 2000). By the early 20th century universities and private schools were offering instruction to elementary, secondary, higher education and vocational learners (Willias, 1994).

Based on broadcast technology, correspondence courses evolved to use the broader term, "distance education" which have been augmented with audio, video, and teleconferencing (Moore \& Thompson, 1996). Nipper (1989) divided distance education into three generations linked to production, distribution and communication technologies. Such groupings tend to exist alongside earlier generations for mutual reinforcement.

In the 1960s and 1970s, teleconferencing was compared to face-to-face instruction (Blackwood \& Trent, 1968 , Hoyt \& Fry, 1972) and was found to be just as effective as face-to-face instruction. Since the 1980s, interest in alternative instructional delivery systems has escalated with technological advances of satellites, cable television, fiber optics, microwave, slow scan television, and computer networking (Wood \& Parham, 1996).

Bates (1993) differentiates these as one-way communication (videotapes, television, radio) and two-way communication (telephone, e-mail, video and computer conferencing). The importance of this differentiation is the fact that distance education can be moved from an individual activity that isolates and insulates learners with oneway communication to social learning with interactive two-way communication. The growing body of literature around the importance of social learning (Denials \& Walker, 1996) involves framing the issue, analyzing the alternatives and debating the choices in a public forum.

In the 21st century, the computer, Internet, and World Wide Web are driving the knowledge-based economy and having a direct impact on distance education. Although self-paced tutorials, on-line testing, streaming video, assignment drop-boxes, etc. increase efficiency, it does little to impact the social learning. Computer conferencing (chat rooms) provides synchronous written communication, which has the potential to support reflection, critical thinking, cognitive development and problem solving (Sumner, 2000). This would in turn support higher order learning since "writing as an advanced skill becomes both the means and the expression of critical thinking and problem solving" (Garrison, 1997, p.4).

Hence, chat rooms with topics that allow for the reflection, critical thinking, cognitive development and problem solving would be the goal for the development and delivery of a distance education course. This paper 
describes a Masters in Business Administration (MBA) course in privacy and information security with such a goal and modifications currently implemented.

\section{COURSE SETTING}

The MBA course described in this paper was offered in a large regional university in southeastern USA that had a national and an international reputation for having a high quality Computer Information Systems (CIS) program. The MBA course was created to develop knowledge and understanding of the threats, problems, and origins of privacy and information security and how they came about.

The course utilized the Internet to post course materials in a password-protected web site (Appendix at http://www.cis.gsu.edu/ cstucke/security/) and used WebCT for the back office to organize and administer the course. A Microsoft Conferencing Server was made available for NetMeeting like capabilities (shared application, chat, audio, and video), but no presenters used this capability. The Microsoft Conferencing Server also served as a backup chat room in the case of disaster (which happened once) allowing participants to switch over into the other chat room.

Students logged into this course from a variety of locations: university computer lab, work, and home. Some groups identified a computer lab where they met in the same physical location allowing face-to-face teamwork within the virtual class. Students who logged into WebCT chat rooms needed to open a firewall port which some employers prohibited., resulting in the student dropping the course or finding another location.

\section{MOTIVATION}

There were several motivations to teach on-line. The first was a personal interest in using technology to facilitate education by creating a learning community or social education as described in the literature. A second motivation was to create a body of knowledge on computer security and privacy. This was built by asking students and presenters for permission to reuse their materials without attribution in later courses. Another motivation was the physical and time constraints of the facilities. With a limited number of 'prime time' slots available in classrooms, a viable option was to go with a virtual classroom to free the course from the constraint of time and geography. Examples of the later motivation were students transferred to another state or business people on the road who were able complete the course. Also from the instructor's perspective, this allowed experts in the field to present lectures, answer questions and interact from around the world without being in physical attendance.

\section{NEED}

This course was a highly sought after three-hour elective for MBA students interested in computer security. While created for CIS and Accounting majors, this course attracted other MBA and graduate students. Instruction of the course alternated between CIS and Accounting faculty and was offered five times during the year (including mini-semesters), with an average class size of 30. The demographics were split between men (66\%) and women $(34 \%)$ with a variety of ethnic and business backgrounds, which were represented in the MBA program as a whole.

\section{PHILOSOPHICAL GOALS}

The goal of the course was to support reflection, critical thinking, cognitive development and problem solving as they relate to privacy and information security. To realize this goal, real world experts were brought in to add depth, insights and interest to topics within the course while creating a learning community.

\section{PLANNING}

Because the course was cross-listed with the Accounting Department, the fall of 2001 was spent in multiple meetings and through electronic correspondence with past instructors to confirm the goals for the course. After analyzing online resources, updating past material and creating new content, a web page was created (Appendix at 
http://www.cis.gsu.edu/ cstucke/security/) that linked all of the materials together within a secure, passwordprotected web site.

Based on accounting's successful use of chat rooms, the existing chat logs were reviewed to better understand the flow of questions and answers. Existing cases were revised and augmented by additional assignments. The additional assignments provided students with real world and timely experience that allowed student the opportunity to keep pace with the changing security field. For example, one assignment was to select two organizations, one of which had to be a commercial entity. Students analyzed its privacy and security policies, compared and contrasted their analyses with other students as well as with available best-practices policy templates. This assignment allowed students to see real world implementation of policy in context and observe that when more money or greater trust was at stake, organizations typically spend more time making sure they have appropriate, robust policies in place.

To motivate students, $20 \%$ of the grade was allocated for individual participation. This encouraged students to speak. But with 35 students, an instructor, and limited number of chat rooms available, the first class was a 2.5 hour chaotic challenge. To solve this problem, the class was broken into seven small groups of four to five students and another WebCT classroom was added to give a total of eight chat rooms (four logged chat rooms is the maximum for each WebCT classroom). Each group was assigned a chat room and identified a spokesperson for each session. The spokesperson served as a liaison between the group and the class chat room. This new arrangement was proved to be successful.

\section{GROUPS}

Groups were self-formed after a brief introduction to the Tuckman model of group formation provided in the first class meeting. With this group structure, having a single spokesperson forced a change in grading from individual participation to group participation. This new reality meant that $20 \%$ of a class grade was now based on a peer evaluation that took place at the end of the term. Therefore, if a student carried more than his/her load in the group, then he/she received more than his/her share based of the group points assigned by the instructor.

Another discovery was the need to exercise good management principles to prevent a surprise at the end of the course. For example, one student thought all the group work looked really great and so he did not contribute anything because the work was getting done without him. He found it made a substantial difference in the course grade because group work was about $60 \%$ of the overall course $(40 \%$ for the group projects and $20 \%$ for participation) leaving $40 \%$ for the two exams in the course.

As a result, a mid-term peer evaluation was instituted strictly for feedback to the members of the group. Average scores were provided to the group allowing discussion within the group as to whether each group member felt he/she was reasonably rewarded his/her effort at mid-term. Just as in the real world, this gave colleagues feedback, so that they have the opportunity to make adjustments.

\section{PRESENTERS}

Prior to the start of the course, permission to reuse presenter's materials without attribution in later courses is secured. The syllabus was written so that students understood that their products in the course (including chat logs) would be available for future classes as well. This allowed a topic to be revisited each semester based on the body of knowledge from previous experts' presentations as well as on-line chat containing the questions and answers from students and the experts. Typically the existing chat logs for a particular session topic were supplied after the current semester's session took place, so as not to spoil the presentation for the expert or the students even though presenters may change from semester to semester. This growing collection of chat logs gives students a chance to see a broad range of presentation, questions and answers. The body of knowledge is therefore built upon when different experts covered slightly different areas and shared different experiences. This creates an enriched environment to support student learning although the volume may become overwhelming. 
All external presentations were interactive and each presenter used one of the following strategies: 1) Prepared lecture notes supporting a PowerPoint presentation. These notes were cut and pasted into the chat window as students viewed the relevant slide. Following the presentation in slide sequence, the presenter paused for questions and answered or asked probing questions to determine student understanding. 2) Walked through the PowerPoint slides with short, relevant comments where there were not a lot of additional initial comments. Presenter immediately moved to questions and answers or probing questions. 3) White papers or full tutorials were provided prior to class. Presenter took questions and answered or asked probing questions. The teams then entered their questions or answers. Teams were also asked not to queue the questions more than three deep.

\section{CASES}

Rather than cases used in the past as the primary mode of policy analysis and creation, real world examples were utilized to give students a more realistic perspective. Information security and privacy policy studies addressed policies for two existing organizations. The assignment was to compare and contrast these with each other and with standard "templates" of best practices. A problem evolved when students "acquired" confidential corporate policies for this analysis, in spite of a requirement that confidential materials not be used. Students were redirected to available, public documents typically from government and educational organizations. Sanitized or scrubbed examples were also offered as models. Groups then posted their analyses before the deadline for submission. Each group then reviewed and critiqued the other groups' papers identifying the best overall content and the best techniques for presenting the analyses.

Two techniques for critiquing include tabular side-by-side representation of organization A, organization B, and best practice template. This facilitates direct comparison. Others use paragraph prose to discuss the differences (and similarities).

The second assignment was an analysis of an information security technology to show potential uses within/by a corporation, potential pitfalls, and recommended decision mechanisms. The challenge was to take students to a deeper level of investigation and understanding that supported a management decision about use of the technology rather than just repeating course materials. By providing an example and approving topics, this assignment was now more effective. An issue with this assignment was the technology changes, but not rapidly enough to create new topics on a continuous basis. The questions became, "Do students get to use the same topics each session? Does one provide the previous students' works as background and enrichment and require the current students to select different topics?"

\section{SCENARIOS}

Brief scenarios were used to verify student understanding. In some instances, presenters provided case studies for students to analyze and solve. After groups complete and post their analysis, the presenter/expert provided feedback on the students' work. Also, a best practice solution was provided. A second case study that appears in the class notes was rarely completed in class. However, this was typically a question found on the next exam for the student to analyze on an individual basis just as they had analyzed the first case as a group.

\section{TESTING}

Exams were typically multiple-choice, short answer, and paragraph answers. The first portion of the exam tested basic understanding of terms and concepts (and where in the course materials the information originated). The second part of the exam was the scenario analysis referenced above. The student had to identify all privacy and security concerns and how they would address these given what had been studied thus far. Even though three hours were allowed for the exam, the student must be knowledgeable of the course materials in order to quickly identify the problem and then move to the reference for the solutions. The exams were available during a 24-hour window on the scheduled day of the class. The instructor was available on-line in chat during the regular class time and available via e-mail during other times but with no guaranteed response time. Most students took the exam during or overlapping the normal class time. 


\section{CLASS STRUCTURE}

A typical class included a short scenario for group analysis that allowed/required the group to exercise the topic just discussed. Groups then posted their analyses to a bulletin board. This was somewhat competitive to see who finished first and/or has the best analysis. Then, groups presented their analyses in the chat room for comments from other groups and the instructor/guest presenter. In some cases, groups were asked to analyze the other groups' postings to select the best point or two from each of the other group's posted work. This greatly enhanced the quality of their initial responses.

Typically each student would have two windows open. One would be a chat room for the general class and the other would be a chat room for their group. The spokesperson would be the liaison between the group and the class to produce either questions or solutions for presentation back to the class. At the end of the class, if there were questions that did not get asked they can be posted and answered. That worked extremely well.

\section{EVALUATION OF THE COURSE}

The course was a success as viewed by both the students and instructor. Student satisfaction, as measured by the Student Evaluation of Instructor Performance (SEIP) scores collected for each class at the end of the semester for the overall teaching effectives course ratting was 4.0 on a scale of 1 (low) to 5 (high). This was in line with the departmental average of 4.04. Students overall ratting for the worth of the course in comparison with others they had taken at this University was 4.0, which was in line with the departmental average of 4.04. However, the instructor was not satisfied with his performance and immediately implemented change to improve the course to follow as reflected in this paper.

\section{DISCUSSION AND RECOMMENDATIONS}

The course goals were met to support reflection, critical thinking, cognitive development and problem solving through the creation of social learning in a virtual classroom. A body of knowledge was also created to build upon for the future.

Given this success, a concern remains that instructors cannot control for students cheating by the teams and individuals involved in distance education. Given the topic of this MBA course (privacy and information security), an authentication system is needed to insure academic integrity as distance education moves forward.

Recommendations and preparation for each class would be to: 1) review on-line materials to insure that they are current and ALWAYS check Web links, 2) encourage student identification of additional / better materials to increase the body of knowledge, 3) search for compelling and humorous / entertaining materials on relevant topics to hold student attention, 4) engage external experts and practitioners to ground the students' knowledge in real world experience, and 5) make the course topics relevant to students with brief comments providing the view from experts/authors/faculty within student's disciplines.

Note: Parts of this paper were presented at the European Applied Business Research Conference in Venice, Italy (June 2003.)

\section{REFERENCES}

1. Bates, T. 1993. "Theory and Practice in the use of Technology in Distance Education" D. Keegan (Ed.) Theoretical Principals of Distance Education (New York, Routledge).

2. Blackwood, H \& Trent, C 1968. "A Comparison of Effectiveness of Face-to-Face and Remote Teaching in Communicating Educational Information to Adults" (Report No. KUJ40615). Manhattan, Kansas State University, Cooperative Extension Service (ERIC No. ED 028 324).

3. Denials, S. \& Walker, T. 1996. "Collaborative Learning: Improving Public Deliberation in EcosystemBased Management”. Environmental Impact Assessment Review, 16, pp. 71-102. 
4. Garrison, D 1997. "Computer Conferencing: The Post Industrial Age of Distance Education", Open Learning, 12(2), pp. 3-11.

5. Hoyt, D. P. \& Fry, D. 1972. "The Effectiveness of Telecommunications as an Educational Delivery System" (Report No. 2G035). Manhattan, Kansas State University (ERIC No. ED 070 318).

6. Moore, M. G. \& Thompson, M. M. 1996. "The Effects of Distance Learning: A Summary of Literature" (Research Monograph No. 2) Athens: Southeastern Ohio Telecommunications Consortium (ERIC No. ED $330321)$.

7. Nipper, S. 1989. "Third Generation Distance Learning and Computer Conferencing” R. Mason \&A. Kaye (Eds) Mindwave Communication, Computers and Distance Education (Toronto, Pergamon Press).

8. Sumner, J. 2000. "Serving the System: A Critical History of Distance Education", Open Learning, Nov, Vol. 15 Issue 3.

9. Verduin, J. \& Clark, T. 1991. Distance Education: the Foundation of Effective Practice (San Francisco, Jossey-Bass).

10. Willias, B. 1994. (Ed.) Distance Education: Strategies and Tools (Englewood Cliffs, NJ, Educational Technology).

11. Wood, J. B. \& Parham, I. A. 1996. "Distance Learning: Videoconferences as Vehicles for Faculty Development in Gerontology/Geriatrics”. Educational Gerontology, Jan/Feb:96, Vol 22 Issue 1, p.105, 11p

\section{NOTES}

